\title{
The Impact of the Upgrading of the Industrial Structure on the Urban Employee Basic Medical Insurance Fund: An Empirical Study in China
}

\author{
Meng Zheng (iD) ${ }^{1,2}$ \\ Junli Zhu (iD) ${ }^{1,2}$ \\ 'School of Public Health, Capital Medical \\ University, Beijing, People's Republic of \\ China; ${ }^{2}$ Research Center for Capital \\ Health Management and Policy, Beijing, \\ People's Republic of China
}

Background: During the transformation of economy to a high-quality level in China, industrial restructuring and upgrading have played an important role. The upgrading of the industrial structure has affected not only the development in society and economy but also other fields, thereby having great impact on social security. In recent years, with the aging of the population and economic development, the social medical insurance fund is undertaking more payment pressure. However, the existing research rarely focuses on the impact of industrial structure upgrading on medical insurance.

Objective: The main aim of this study was to analyze the impact of the upgrading of industrial structure on the income and expenditure of the urban employee basic medical insurance fund.

Methods: China's provincial panel data from 2007 to 2018, collected by the National Bureau of Statistics of China, were used to establish a panel regression model in order to investigate the impact of the upgrading of the industrial structure on the income and expenditure of the urban employee basic medical insurance fund.

Results: The research showed that the upgrading of the industrial structure, in combination with the internal upgrading in the tertiary industry, had a positive impact on the income and expenditure of the urban employee basic medical insurance fund and that there were regional differences. The simple upgrading of the three major industries had no effect on the income or expenditure of the urban employee basic medical insurance fund. In addition to the upgrading of industrial structure, other factors such as the average salary of employed persons in urban units, the proportion of retirees among all insured persons in urban employee basic medical insurance and the expenditure of urban employee basic medical insurance were also found to have impact on the income of urban employee basic medical insurance. Moreover, the expenditure of urban employee basic medical insurance was associated with the proportion of retirees among all insured persons in urban employee basic medical insurance, GDP and an aging population.

Conclusion: In the context of the upgrading of the industrial structure, measures such as strengthening employment and income security, delaying retirement, adjusting birth policy, strengthening the scientific management of personal accounts and accurately positioning the regional industrial structure were suggested to be adopted in order to minimize the payment pressures on the urban employee basic medical insurance fund.

Keywords: industrial structure upgrading, urban employee basic medical insurance, panel regression model, employment structure

\section{Introduction}

In the past few decades, China's economic development has had remarkable achievements. In the 'troika' that drives China's economic growth, foreign trade 
has always been the most important aspect. However, the global economy and the growth rate of China's import and export trade continued declining as a result of the subprime mortgage crisis in 2008. Both theory and practice have proved that economic development affects industrial structure and that the upgrading of industrial structure also affects economic development. ${ }^{1,2}$ In China, changes in the industrial structure can promote economic growth, ${ }^{3}$ and changes in the industrial structure have also contributed to the high-quality development of China's economy in recent years. ${ }^{4}$ To maintain economic stabilization and development, China must change its economic development model (which is overly dependent on foreign trade exports), adjust its economic structure and promote industrial transfer and upgrading.

As China's largest trading province, Guangdong Province is particularly vulnerable. In 2008, Guangdong Province took the lead in proposing a strategy of advancing industrial transfer and labor transfer, which is called "vacating the cage to change birds", and subsequently introduced a series of policies to promote regional industrial upgrading. Other provinces have followed suit. Since 2015, China started to promote supply-side structural reform and adopted a series of measures including "decapacity, deinventory, and deleveraging", aiming to realize the adjustment and optimization of China's industrial structure. In recent years, relieving those unessential functions for Beijing as the capital of China was accepted to be an important measure in terms of promoting regional industrial upgrading. The upgrading of the industrial structure is achieved by deconstructing urban functions that are incompatible with the functions of the capital. It can be seen that industrial structure upgrading is an important part of the process of promoting regional economic development and improving the economic development pattern. Industrial structure adjustment drives the transfer of labor, which not only promotes economic development but also changes the social employment structure. Changes in the industrial structure reflect the requirements of economic development and also affect the development of all aspects of society. As an important social system closely related to the people, the social security system is inevitably affected by adjustments to the industrial structure.

China's previous medical insurance system for urban employees primarily consisted of the Government Insurance Scheme (GIS) and Labor Insurance Scheme (LIS). Chinese government launched a health insurance reform in 1998 and established Urban employee basic medical insurance (UEBMI) system by merging the GIS and LIS. $^{38}$ UEBMI is a mandatory insurance program based on employment and run by government. It is the most mature and complete insurance plan in China's insurance system and financed by payroll taxes paid by both employers (6\%) and employees (2\%). ${ }^{38,41}$ As of the end of 2019 , the number of people participating in UEBMI was about 330 million, accounting for about $25 \%$ of the total population covered by social medical insurance in China. The funds raised are divided into social pooling account (SPA) and individual medical savings accounts (MSAs), specifically, $70 \%$ of the employers' contributions go into SPA and $30 \%$ is deposited into MSAs. The part paid by the employee is fully deposited into MSAs, ${ }^{38,41}$ The SPA is primarily used for inpatient services and outpatient services for catastrophic illness and administrated by the local government with the different benefits. MSAs are primarily used for outpatient services, as well as for drug purchase from contracted providers. ${ }^{38}$

In recent years, with the increasing aging of the population, the gradual rise of medical expenses and other complicated factors, social medical insurance, including UEBMI, is facing pressures on fund payments. According to data disclosed by the National Bureau of Statistics of China, in the past ten years, the expenditure by the UEBMI has been increasingly rising. In 2019, the expenditure by the UEBMI increased by $18.3 \%$ compared with the previous year, and it accounted for $5.3 \%$ of general public budget expenditure. Petty-Clark Theorem and Kuznets Theorem point out: the difference in relative income among different industries will encourage workers to move to industries that can earn higher incomes. ${ }^{43}$ With the gradual increase in the level of per capita national income, the labor force will first shift from the primary industry to the secondary industry, and then continue to move to the third industry. There is a strong correlation between industrial structure and employment structure. ${ }^{18,19}$ The upgrading of the industrial structure will inevitably cause changes in the employment structure, thereby affecting the flow of labor. As the above, the UEBMI takes employees of urban units as its main participants, so when the social employment structure changes, the structure of its participants will change accordingly and in turn leads to changes in the UEBMI funding. However, the current research on the factors that influence social medical insurance funds rarely looks at industrial structure upgrading. This paper established a panel regression model to explore the impact of industrial structure 
upgrading on the income and expenditure of UEBMI, thereby providing policy recommendations for relevant departments.

\section{Literature Review and Theoretical Framework}

Research on social medical insurance funds and the factors influencing health costs started relatively early, and a large amount of literature has been accumulated. Scholars mainly conduct research on economic factors, social factors, medical technology, and medical and health systems. Those studying economic factors mainly choose GDP and income level, while the studies on social factors mainly look at the impact of population aging and life expectancy. $^{5-12}$ Medical technology developments and health system adjustments also affect health expenditure. $^{6,30}$ Only a few scholars have studied the impact of industrial structure upgrading on social security, including social pension insurance and social medical insurance. The following is a literature review based on the theoretical framework of this paper.

As mentioned earlier, the UEBMI is paid by employers and employees based on a certain percentage of the average wage level of the employees, and retired employees will no longer pay. Obviously, the number of payers, the payment base, and the payment standard will have a positive relationship with medical insurance income. The proportion of active employees or retirees, the degree of aging of the society and the level of urbanization may be important influencing factors. The level of contributions may be affected by the average social salary and the level of economic development. The research on the influencing factors of social medical insurance income revolves around these aspects. Huang and Cai show that the factors affecting the income of UEBMI mainly include the number of payers, the payment base, the payment standard, salary level and urban population. ${ }^{31,32}$ Zhao using the national time series data of China from 1998 to 2013 suggests that average wage level and the number of active employees in the insured population have important impact on the income of UEBMI. ${ }^{34}$ Similarly, Gu finds that other than average wage level, the number of insured population and the proportion of urban workers in the urban population are also important for the income of UEBMI using the data from 1998 to $2017 .{ }^{35} \mathrm{Jia}$ and Zhao use data from 2004 to 2015 and finds that for every additional unit of the aging population, the per capita income of the employee's medical insurance fund will increase by 1.315 units. ${ }^{40}$ Yang shows that economic development is closely related to the development of social security. ${ }^{42}$ China's current medical security system is based on the pay-as-you-go system, which determines the income and expenditure of the basic medical insurance fund in the current year according to the principle of "set expenditure by income and balance of income and expenditure". Therefore, the expenditure of UEBMI is another important factor that affects the income of UEBMI.

The impact factors of social medical security expenditure or health expenditure are investigated by a substantial number of studies worldwide. The results commonly show that per capita GDP, population aging, education level and residents' income have an important impact. Newhouse shows that population aging and people's income level are important factors affecting the increase of medical expenditure. ${ }^{9}$ Francia L shows that GDP, medical service supply and medical service demand have a significant impact on health expenditure, and the aging of population is also a factor that cannot be ignored. ${ }^{46}$ Later, Rahman and Deepak find that GDP, per capita income and literacy rate have an important impact on health expenditure in India $^{44,45}$ Ellis makes a survey of Australians aged 45 and over and shows that high fixed expenditures are positively associated with age. ${ }^{39} \mathrm{Li}$ et al uses China's province-level data from 2005 to 2014 and finds that economic growth, population aging and medical cost growth have an positive impact on the expenditure of medical insurance. ${ }^{8}$ Jia and Zhao further gives that for every additional unit of population aging, the per capita expenditure of UEBMI will increase by 1.786 units. $^{40}$

The result of the above research provides a basis for the construction of the model and the selection of control variables. In fact, the upgrading of industrial structure is also an important factor affecting the fund of UEBMI. Mi et al first propose the use of the social security level industrial adaptability coefficient (CSI) to analyze the adaptability relationship between the social security level and adjustments to the industrial structure. ${ }^{13} \mathrm{Mu}$ et al use a panel data model for an empirical study of the impact of industrial structure upgrading on the ability to reduce pension contribution's space. ${ }^{14} \mathrm{Fu}$ et al, taking Shandong Province in China as an example, analyze the impact of industrial restructuring and upgrading on social pension insurance. ${ }^{15}$ Social medical insurance is far more complicated than social pension insurance. Social pension insurance provides stable income source for retirees and 
ensures the basic life demand of retirees. The insured receive a monthly pension only after retirement, before retirement does not consume social pension insurance fund. But the social medical insurance is designed to reduce the economic burden of illness, medical expenses are reimbursed at a certain rate. No matter be in before and after retirement, the insured can consume fund of social medical insurance. However, the current research on the factors that influence social medical insurance funds rarely looks at industrial structure upgrading. The following describes how the industrial structure upgrading affects the mechanism of UEBMI's income and expenditure.

Theory and practice have proved that the industrial structure and the employment structure are inseparable: there is a strong correlation between the industrial structure and the employment structure. ${ }^{16-18}$ Drucker uses the data of the United States from 1987 to 1997 to analyze the industrial structure and regional manufacturing employment change. ${ }^{19}$ Hannon et al showed that good industrial development policies have a positive impact on the promotion of employment. ${ }^{20}$ Earlier, the Petty-Clark law is used to show that the employment population will change with changes in the industrial structure. The industrial structure, which determines the employment structure, also determines the employment stability and income level, and at the micro level affects the individual's ability to pay. On the one hand, the upgrading of the industrial structure promotes the transfer of the labor force from rural to urban areas and increases the number of employees paying for medical insurance, so the income of the UEBMI increases. On the other hand, the upgrading of the industrial structure can promote employment stability and increase wages, to a certain extent. This makes UEBMI's payment base increase, so the income of the UEBMI increases. In an industrial environment with employment stability and high wage levels, the participation rate and the payment base of the UEBMI will increase, so the income of the UEBMI will increase accordingly.

The upgrading of industrial structure changes the education level and income level of employees in the region. Many studies show that education level and income level are important factors that affect residents' choice of medical treatment. For example, people with a higher level of education and income are more concerned about their health and are more willing to go to a higher level hospital for treatment. ${ }^{21-27}$ Blackwell et al show that socioeconomic status such as education and income are associated with doctor contacts or visits. ${ }^{21}$ Ellis shows that more affluent consumers prefer the hospitals of higher cost and higher quality. Some demographic characteristics include education level, age and sex are also important factors which impact the use of medical services. ${ }^{23}$ Gao shows that medical choice behavior is influenced by demographic characteristics, medical services and health status. And patients with higher education levels are more likely to seek medical treatment in tertiary hospitals (the high-grade hospital). ${ }^{24}$ Through the influence of education and income level, people of different occupations will also have different medical options. The upgrading of the industrial structure has changed the distribution of regional occupations. On the one hand, it has absorbed a more high-quality and better-educated labor force. On the other hand, the income level of employees has increased. In the process of the upgrading of the industrial structure, the overall cultural level and income of the labor force in the region increases and the labor population in the region becomes more likely to choose high-quality and high-cost medical institutions for medical treatment, so the upgrading of the industrial structure may, to some extent, increase the expenditure of the UEBMI. A chart of the impact of the upgrading of the industrial structure on the UEBMI is shown in Figure 1.

\section{Data and Variables}

This paper employed a balanced panel data of 31 Chinese provinces from 2007 to 2018, which was downloaded from the data query interface of the official website of the National Bureau of Statistics of China. This paper mainly studied the impact of the upgrading of the industrial structure on the UEBMI fund of China. So the per capita income of the UEBMI (PIN) and the per capita expenditure of the UEBMI (POUT) were taken as dependent variables. The core independent variable was the industrial structure upgrading coefficient, which was divided into the industrial structure upgrading coefficient 1 (ISUC1) and the industrial structure upgrading coefficient 2 (ISUC2). We used CPI index to eliminate inflation for all economic indicators. Table 1 shows the specific calculation.

ISUC1 represented the upgrading of the three major industries and was calculated based on the output value of the three major industries as a proportion of GDP. ${ }^{14,28}$ Because of the limitations of the data collection, we used the value-added of the three major industries to calculate this. The specific formula is as follows: 


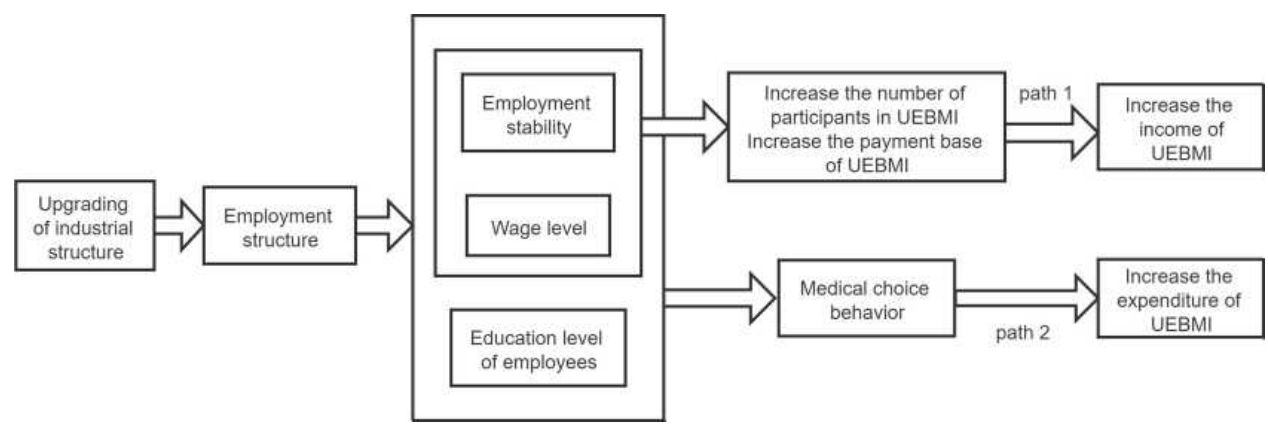

Figure I The impact path of industrial structure upgrading on UEBMI.

$$
\mathrm{ISUC1}=\sum_{i=1}^{3} q_{i} \times i=q_{1} \times 1+q_{2} \times 2+q_{3} \times 3
$$

Where $q_{i}$ is the ratio of the value-added of the i-th industry to the total value-added of the three industries.

On the same basis as ISUC1, ISUC2 introduced the internal level upgrading of tertiary industry, reflecting the degree of transformation of life services industries in the tertiary sector to production services industries. ${ }^{14,29}$ The employment stability and wage stability of life services industries and production services industries in the tertiary sector are also different, which will affect the payment behavior for the UEBMI. Life services industries mainly include wholesale and retail, accommodation and catering; the employment stability and income stability of these industries are worse than those of production services and other industries. The specific formula is as follows:

$$
\begin{aligned}
\mathrm{ISUC} 2 & =\sum_{i=1}^{2} q_{i} \times i+q_{3} \times 3 \times \chi_{3 p} / \chi_{3 l} \\
& =q_{1} \times 1+q_{2} \times 2+q_{3} \times 3 \times \chi_{3 p} / \chi_{3 l}
\end{aligned}
$$

Where $q_{i}$ is the same as for ISUC1, and $\chi_{3 p} / \chi_{3 l}$ is the ratio of internal production services industries in the tertiary industry (real estate; transportation, warehousing and postal services industries; financial industries; other industries) to the life services industries (wholesale and retail industries; accommodation and catering industries).

Based on the previous literature, the study selected control variables from economic development, population aging, employment status and ability to pay for the income of UEBMI. Drawing on the previous literature, this paper chose per capita GDP as the measurement variable for economic development. For the aging of the population, many literatures select the proportion of the 65-year-old

\begin{tabular}{|c|c|c|c|c|}
\hline Variables & Definition & Obs & Mean & Std. \\
\hline PIN & $\begin{array}{l}\text { Per capita income of the UEBMI=Total income of the UEBMI/Total number of participants of the } \\
\text { UEBMI }\end{array}$ & 372 & 2194.24 & 969.45 \\
\hline POUT & $\begin{array}{l}\text { Per capita expenditure of the UEBMI=Total expenditure of the UEBMI/Total number of the } \\
\text { participants of the UEBMI }\end{array}$ & 372 & 1737.76 & 752.42 \\
\hline ISUCI & industrial structure upgrading coefficient I & 372 & 2.34 & 0.13 \\
\hline ISUC2 & industrial structure upgrading coefficient 2 & 372 & 5.35 & 1.95 \\
\hline ELD & The dependency ratio of the elderly & 372 & 0.13 & 0.03 \\
\hline RET & Proportion of retirees in the number of insured persons of the UEBMI & 372 & 0.28 & 0.06 \\
\hline WAGE & Average salary of employed persons in urban units & 372 & $41,071.60$ & $15,693.65$ \\
\hline PGDP & per capital GDP & 372 & $36,463.94$ & $19,728.30$ \\
\hline MIE & The expenditure of the UEBMI & 372 & $\mathrm{I}, 476,78 \mathrm{I}$ & $1,469,683$ \\
\hline UR & The unemployment rate & 372 & 0.03 & 0.01 \\
\hline IR & The illiteracy rate & 372 & 0.07 & 0.06 \\
\hline
\end{tabular}
population in the region. But based on the policy that the

Table I Variables and Descriptive

Notes: Take log of PIN, POUT, WAGE, PGDP and MIE to eliminate the influence of dimension. Consumer Price Index (CPI) is used to process financial data such as PIN, POUT, WAGE, PGDP and MIE to eliminate the impact of inflation. The annual CPI of each province disclosed in the official website of the National Bureau of Statistics of China is the link index, which needs to be converted into the fixed-base relative index based on 2007 according to the following formula: (fixed-base relative index) ${ }_{\mathrm{t}}=($ link index $)_{t} \times(\text { fixed-base relative index })_{t-1}$. PIN, POUT, WAGE, PGDP and MIE raw prices are divided by the fixed-base relative index of CPI to get the inflation-adjusted prices. 
retired population no longer pays, this study believes that the proportion of the retired population is more appropriate. Considering that UEBMI is based on employment, so the regional employment situation affects the number of insured populations. And the regional average wage affects the ability of pay. The regional unemployment rate as the measurement variable and the regional average wage was also selected as the control variable. At last, in view of the SPA's "real-term balance" pay-as-you-go financing model, medical insurance expenditure was also included as a control variable in the model. For the analysis of the impact of industrial structure upgrading on the expenditure of UEBMI, in addition to the control variables of the income model, we also included the regional elderly dependency ratio and the regional educational level referring to the existing literature. Table 1 presents the variables used in the models along with their definitions and descriptive statistics.

\section{Estimation Framework}

We set up a panel regression model to verify the impact of industrial structure upgrading on the income and expenditure of the UEBMI. Using stata 11 for the regression analysis of panel data, the specific regression model is as follows:

$$
\begin{aligned}
\mathrm{PIN}_{i t}= & \mu_{i t}+\beta_{1} I S C U 1_{i t} \mid I S U C 2_{i t}+\beta_{2} R E T_{i t}+\beta_{3} W A G E_{i t} \\
& +\beta_{4} P G D P_{i t}+\beta_{5} M I E_{i t}+\beta_{6} U R_{i t}+\varepsilon_{i t} \\
\text { POUT }_{i t}= & \mu_{i t}+\beta_{1} I S U C 1_{i t} \mid I S U C 2_{i t}+\beta_{2} R E T_{i t} \\
& +\beta_{3} W A G E_{i t}+\beta_{4} P G D P_{i t}+\beta_{5} E L D_{i t}+\beta_{6} I R_{i t} \\
& +\varepsilon_{i t}
\end{aligned}
$$

\section{Results}

This paper mainly discussed the impact of the upgrading of industrial structures on the income and expenditure of

\begin{tabular}{|c|c|c|c|c|c|c|}
\hline \multirow{3}{*}{$\begin{array}{l}\text { Dependent Variable } \\
\text { Independent variable }\end{array}$} & \multicolumn{6}{|l|}{ PIN } \\
\hline & \multicolumn{2}{|c|}{ All Provinces } & \multicolumn{2}{|l|}{ Eastern } & \multicolumn{2}{|c|}{ Midwestern and Northeastern } \\
\hline & & & & & & \\
\hline ISUCI & $\begin{array}{l}-0.110 \\
(0.181)\end{array}$ & & $\begin{array}{l}-0.374 \\
(0.51 \mathrm{I})\end{array}$ & & $\begin{array}{l}-0.186 \\
(0.139)\end{array}$ & \\
\hline ISUC2 & & $\begin{array}{l}0.015 * * \\
(0.007)\end{array}$ & & $\begin{array}{l}0.032^{* * * *} \\
(0.007)\end{array}$ & & $\begin{array}{l}0.005 \\
(0.010)\end{array}$ \\
\hline RET & $\begin{array}{l}\text { I.463*** } \\
(0.450)\end{array}$ & $\begin{array}{l}\text { I.544*** } \\
(0.435)\end{array}$ & $\begin{array}{l}2.147 * * \\
(0.731)\end{array}$ & $\begin{array}{l}3.070 * * * \\
(0.566)\end{array}$ & $\begin{array}{l}\text { I.246** } \\
(0.453)\end{array}$ & $\begin{array}{l}1.229 * * \\
(0.446)\end{array}$ \\
\hline WAGE & $\begin{array}{l}0.252 * \\
(0.132)\end{array}$ & $\begin{array}{l}0.252 * \\
(0.131)\end{array}$ & $\begin{array}{l}0.005 \\
(0.331)\end{array}$ & $\begin{array}{l}-0.014 \\
(0.318)\end{array}$ & $\begin{array}{l}0.203 \\
(0.147)\end{array}$ & $\begin{array}{l}0.214 \\
(0.146)\end{array}$ \\
\hline PGDP & $\begin{array}{l}0.030 \\
(0.066)\end{array}$ & $\begin{array}{l}0.078 \\
(0.068)\end{array}$ & $\begin{array}{l}-0.292^{*} \\
(0.15 I)\end{array}$ & $\begin{array}{l}-0.149 \\
(0.156)\end{array}$ & $\begin{array}{l}0.117 \\
(0.085)\end{array}$ & $\begin{array}{l}0.138 \\
(0.096)\end{array}$ \\
\hline MIE & $\begin{array}{l}0.259 * * \\
(0.099)\end{array}$ & $\begin{array}{l}0.246 * * \\
(0.098)\end{array}$ & $\begin{array}{l}0.008 \\
(0.07 I)\end{array}$ & $\begin{array}{l}0.052 \\
(0.074)\end{array}$ & $\begin{array}{l}0.379 * * * \\
(0.096)\end{array}$ & $\begin{array}{l}0.369 * * * \\
(0.101)\end{array}$ \\
\hline UR & $\begin{array}{l}-0.966 \\
(2.604)\end{array}$ & $\begin{array}{l}-1.225 \\
(2.591)\end{array}$ & $\begin{array}{l}-4.122 \\
(3.008)\end{array}$ & $\begin{array}{l}-4.227^{*} \\
(2.290)\end{array}$ & $\begin{array}{l}0.983 \\
(2.937)\end{array}$ & $\begin{array}{l}0.909 \\
(2.944)\end{array}$ \\
\hline Constant & $\begin{array}{l}0.825 \\
(2.103)\end{array}$ & $\begin{array}{l}0.172 \\
(1.912)\end{array}$ & $\begin{array}{l}10.611 \text { |*** } \\
(3.174)\end{array}$ & $\begin{array}{l}7.455^{* *} \\
(2.944)\end{array}$ & $\begin{array}{l}-0.837 \\
(1.685)\end{array}$ & $\begin{array}{l}-1.454 \\
(1.477)\end{array}$ \\
\hline R2 & 0.956 & 0.957 & 0.956 & 0.961 & 0.969 & 0.969 \\
\hline $\mathrm{F}$ & $6.72^{* * * *}$ & $8.43^{* * *}$ & $16.98 * * *$ & $34.33 * * *$ & $7.89 * * *$ & $8.50^{* * *}$ \\
\hline
\end{tabular}
the UEBMI. Table 2 shows the impact of industrial

Table 2 Panel Regression Results of PIN as Dependent Variable

Notes: I) We divide China into two regions: eastern, midwestern and northeastern. The eastern region includes 10 provinceslcities of Beijing, Tianjin, Hebei, Shanghai, Jiangsu, Zhejiang, Fujian, Shandong, Guangdong and Hainan; the midwestern and northeastern regions include the remaining 21 provinces in China. China is divided into eastern region, central region, western region and northeast region. In this study, ten provinces/cities in eastern China are selected, whose economic development level is higher than that of other provinces. 2) The four models are all fixed-effect models, the time effect is controlled, and the $F$ value is Hausmann test $F$ value under robust standard error. 3) Standard errors are shown in brackets. 4)*** $\mathrm{P}<0.01,{ }^{* *} \mathrm{P}<0.05,{ }^{*} \mathrm{p}<0.1$. 
structure upgrading on the per capita income of the UEBMI. The second and third columns in Table 2 show that ISUC1 had no influence on the per capita income of the UEBMI for all provinces in China, while ISUC2 had a positive influence on the per capita income of the UEBMI. The fourth and fifth columns of Table 2 show that ISUC1 still had no significant effect on the per capita income of the UEBMI in eastern China, but that ISUC2 had a positive effect on the per capita income of the UEBMI in eastern China. The sixth and seventh columns in Table 2 show the impact of industrial structure upgrading on the per capita income of the UEBMI in mid-western and north-eastern China. In these areas of China, neither ISUC1 nor ISUC2 had a significant impact on the per capita income of the UEBMI. In addition, as for the influence of other control variables on the income of UEBMI, the research showed that from the perspective of all provinces in China, without considering regional differences, the RET was positively correlated with the per capita income of UEBMI. The larger the proportion of retirees, the higher the per capita income of UEBMI; The WAGE was positively correlated with the per capita income of UEBMI. The higher the average wage of urban employees, the higher the per capita income of UEBMI; The MIE was positively correlated with the per capita income of UEBMI. The greater the expenditure of UEBMI, the greater the per capita income of UEBMI.

Table 3 shows the impact of the upgrading of the industrial structure on the per capita expenditure of the UEBMI. The second, fourth, and sixth columns of Table 3 represent the impact of ISUC1 on the per capita expenditure of the UEBMI from three viewpoints: all provinces, eastern China, and mid-western and north-eastern China. Whether we look at all the provinces, at eastern China or at midwestern and north-eastern China, ISUC1 had no significant impact on the per capita expenditure of the UEBMI. The third, fifth, and seventh columns of Table 3 show the impact of ISUC2 on the expenditure of the UEBMI from the same three viewpoints. ISUC2 had a positive impact on the per capita expenditure of the UEBMI, and there were regional

Table 3 Panel Regression Results of POUT as Dependent Variable

\begin{tabular}{|c|c|c|c|c|c|c|}
\hline \multirow{3}{*}{$\begin{array}{l}\text { Dependent Variable } \\
\text { Independent variable }\end{array}$} & \multicolumn{6}{|l|}{ POUT } \\
\hline & \multicolumn{2}{|c|}{ All Provinces } & \multicolumn{2}{|l|}{ Eastern } & \multicolumn{2}{|c|}{ Midwestern and Northeastern } \\
\hline & & & & & & \\
\hline ISUCI & $\begin{array}{l}0.009 \\
(0.302)\end{array}$ & & $\begin{array}{l}-0.206 \\
(0.437)\end{array}$ & & $\begin{array}{l}0.085 \\
(0.334)\end{array}$ & \\
\hline ISUC2 & & $\begin{array}{l}0.02 I^{*} \\
(0.012)\end{array}$ & & $\begin{array}{l}0.001 \\
(0.009)\end{array}$ & & $\begin{array}{l}0.033 * * \\
(0.015)\end{array}$ \\
\hline RET & $\begin{array}{l}1.330^{* *} \\
(0.613)\end{array}$ & $\begin{array}{l}1.5 \mid 2^{* *} \\
(0.6 \mid 2)\end{array}$ & $\begin{array}{l}-0.176 \\
(0.861)\end{array}$ & $\begin{array}{l}-0.242 \\
(1.291)\end{array}$ & $\begin{array}{l}1.748^{* *} \\
(0.652)\end{array}$ & $\begin{array}{l}1.800^{* * *} \\
(0.654)\end{array}$ \\
\hline WAGE & $\begin{array}{l}0.211 \\
(0.188)\end{array}$ & $\begin{array}{l}0.206 \\
(0.187)\end{array}$ & $\begin{array}{l}-0.048 \\
(0.323)\end{array}$ & $\begin{array}{l}-0.090 \\
(0.24 I)\end{array}$ & $\begin{array}{l}0.230 \\
(0.228)\end{array}$ & $\begin{array}{l}0.212 \\
(0.227)\end{array}$ \\
\hline PGDP & $\begin{array}{l}0.180 \\
(0.117)\end{array}$ & $\begin{array}{l}0.243^{*} \\
(0.127)\end{array}$ & $\begin{array}{l}-0.137 \\
(0.172)\end{array}$ & $\begin{array}{l}-0.120 \\
(0.182)\end{array}$ & $\begin{array}{l}0.241^{*} \\
(0.119)\end{array}$ & $\begin{array}{l}0.320 * * \\
(0.136)\end{array}$ \\
\hline ELD & $\begin{array}{l}\text { I.596*** } \\
(0.578)\end{array}$ & $\begin{array}{l}\text { I.463** } \\
(0.536)\end{array}$ & $\begin{array}{l}\text { I.487** } \\
(0.589)\end{array}$ & $\begin{array}{l}1.463 * * \\
(0.587)\end{array}$ & $\begin{array}{l}2.052^{*} \\
(1.023)\end{array}$ & $\begin{array}{l}2.056 * * \\
(0.953)\end{array}$ \\
\hline IR & $\begin{array}{l}0.153 \\
(0.533)\end{array}$ & $\begin{array}{l}0.290 \\
(0.500)\end{array}$ & $\begin{array}{l}-0.716 \\
(1.376)\end{array}$ & $\begin{array}{l}-0.641 \\
(1.443)\end{array}$ & $\begin{array}{l}0.45 I \\
(0.617)\end{array}$ & $\begin{array}{l}0.608 \\
(0.560)\end{array}$ \\
\hline Constant & $\begin{array}{l}2.216 \\
(2.383)\end{array}$ & $\begin{array}{l}1.516 \\
(2.068)\end{array}$ & $\begin{array}{l}9.159 * * * \\
(2.400)\end{array}$ & $\begin{array}{l}8.938 * * * \\
(2.34 I)\end{array}$ & $\begin{array}{l}1.028 \\
(2.7 I I)\end{array}$ & $\begin{array}{l}0.449 \\
(2.140)\end{array}$ \\
\hline R2 & 0.960 & 0.961 & 0.966 & 0.966 & 0.965 & 0.967 \\
\hline $\mathrm{F}$ & $3.43 * *$ & $6.4 I^{* * *}$ & $169.57 * * *$ & $52.62 * * *$ & $4.05^{* * *}$ & $3.57 * *$ \\
\hline
\end{tabular}

Notes: The four models are all fixed-effect models, the time effect is controlled, and the $F$ value is Hausmann test $F$ value under robust standard error. Standard errors are shown in brackets. $* * * \mathrm{P}<0.01, * * \mathrm{P}<0.05,{ }^{*} \mathrm{p}<0.1$. 
differences. ISUC2 in the mid-western and north-eastern regions had a significant impact on the per capita expenditure of the UEBMI, while in the eastern region it had no significant impact. In addition, with regard to the influence of other control variables on the expenditure of UEBMI, the research showed that from the perspective of all provinces in China, without considering regional differences, the RET was positively correlated with the per capita expenditure of UEBMI. The larger the proportion of retirees, the greater the per capita expenditure of UEBMI. PGDP and the ELD were positively correlated with the per capita expenditure of UEBMI. Social and economic development and population aging will increase the payment pressure of UEBMI.

The research showed that ISUC1 had no influence on the per capita income or expenditure of the UEBMI. Therefore, this paper only tested the robustness of the independent variable for the ISUC2 model. Table 4 shows the robustness test results for the impact of ISUC2 on the per capita income and expenditure of the UEBMI. When the control variables were added to the model, ISUC2 had an impact on the per capita income and expenditure of the UEBMI. When the time effect and the robust standard error were introduced into the model, ISUC2 still had an impact on the per capita income and expenditure of the UEBMI. We therefore believe that ISUC2 has an impact on the per capita income and expenditure of the UEBMI and that the model is robust.

\section{Discussion}

This study mainly found that ISUC1 had no impact on the income or expenditure of the UEBMI. ISUC2 had a positive impact on the income and expenditure of the

Table 4 Robustness Test Results of Industrial Structure Upgrading Coefficient 2

\begin{tabular}{|c|c|c|c|c|c|c|}
\hline \multirow[t]{2}{*}{ Dependent Variable } & \multicolumn{3}{|l|}{ PIN } & \multicolumn{3}{|l|}{ POUT } \\
\hline & Model I & Model 2 & Model 3 & Model 4 & Model 5 & Model 6 \\
\hline \multicolumn{7}{|l|}{ Independent variable } \\
\hline ISUC2 & $\begin{array}{l}0.200 * * * \\
(0.012)\end{array}$ & $\begin{array}{l}0.034^{* * * *} \\
(0.005)\end{array}$ & $\begin{array}{l}0.015^{* *} \\
(0.007)\end{array}$ & $\begin{array}{l}0.206 * * * \\
(0.015)\end{array}$ & $\begin{array}{l}0.014^{*} \\
(0.007)\end{array}$ & $\begin{array}{l}0.02 I^{*} \\
(0.012)\end{array}$ \\
\hline RET & & $\begin{array}{l}\text { I.740*** } \\
(0.272)\end{array}$ & $\begin{array}{l}\text { I.544*** } \\
(0.435)\end{array}$ & & $\begin{array}{l}2.198 * * * \\
(0.340)\end{array}$ & $\begin{array}{l}1.512^{* *} \\
(0.6 \mid 2)\end{array}$ \\
\hline WAGE & & $\begin{array}{l}0.487 * * * \\
(0.075)\end{array}$ & $\begin{array}{l}0.252^{*} \\
(0.131)\end{array}$ & & $\begin{array}{l}0.752 * * * \\
(0.071)\end{array}$ & $\begin{array}{l}0.206 \\
(0.187)\end{array}$ \\
\hline PGDP & & $\begin{array}{l}0.051 \\
(0.056)\end{array}$ & $\begin{array}{l}0.078 \\
(0.068)\end{array}$ & & $\begin{array}{l}0.425 * * * \\
(0.065)\end{array}$ & $\begin{array}{l}0.243^{*} \\
(0.127)\end{array}$ \\
\hline MIE & & $\begin{array}{l}0.244 * * * \\
(0.036)\end{array}$ & $\begin{array}{l}0.246 * * \\
(0.098)\end{array}$ & & & \\
\hline UR & & $\begin{array}{l}-2.123 \\
(1.704)\end{array}$ & $\begin{array}{l}-1.225 \\
(2.591)\end{array}$ & & & \\
\hline ELD & & & & & $\begin{array}{l}0.420 \\
(0.419)\end{array}$ & $\begin{array}{l}\text { I.463** } \\
(0.536)\end{array}$ \\
\hline IR & & & & & $\begin{array}{l}-0.301 \\
(0.385)\end{array}$ & $\begin{array}{l}0.290 \\
(0.500)\end{array}$ \\
\hline Constant & $\begin{array}{l}6.536 * * * \\
(0.066)\end{array}$ & $\begin{array}{l}-2.016 * * * \\
(0.326)\end{array}$ & $\begin{array}{l}0.172 \\
(1.912)\end{array}$ & $\begin{array}{l}6.265^{* * *} \\
(0.080)\end{array}$ & $\begin{array}{l}-5.715^{* * *} \\
(0.297)\end{array}$ & $\begin{array}{l}1.516 \\
(2.068)\end{array}$ \\
\hline R2 & 0.447 & 0.949 & 0.957 & 0.368 & 0.943 & 0.961 \\
\hline Observations & 372 & 372 & 372 & 372 & 372 & 372 \\
\hline
\end{tabular}

Notes: This table is robustness test results of all provinces in China; Model I is a fixed-effect model with only one independent variable of the ISUC2; Model 2 includes control variables and also use fixed-effect model. Model 3 adds time effect to Model 2 and uses robust standard errors. Models 4,5 , and 6 have the same order of robustness testing as models I, 2, and 3. The difference is that the dependent variables of models I, 2, and 3 is per capita income of the UEBMI, and the dependent variables of models 4 , 5 , and 6 is per capita expenditure of the UEBMI. $* * * P<0.01$, $* * P<0.05$, ${ }^{*} p<0.1$. 
UEBMI, and there were regional differences. ISUC2 had a significant and positive impact on the income of the UEBMI in eastern China, and a significant and positive impact on the expenditure of the UEBMI in mid-western and north-eastern China.

Similar to our findings, $\mathrm{Mu}$ et $\mathrm{al}^{14}$ found that when comparing the influence of two industrial structure upgrading coefficients on the deviation of social pension insurance payments, that the rational upgrading of the industrial structure including the internal upgrading of the tertiary industry has a positive effect on social pension insurance income, and the impact of the ISUC2 on income of the social pension insurance has regional differences, with the effect being more obvious in eastern China. The upgrading at the internal level of the tertiary industry reflects the degree of transformation of the life services industries to the production services industries and other industries. Compared with the life services industries, the production services and other industries have stronger employment stability and wage stability, which leads to an increase in the payment rate and payment base of the UEBMI. Therefore, ISUC2 has a greater impact than ISUC1 on the income of the UEBMI. We should take some measures such as strengthening employment and income security to guarantee the income of UEBMI.

China is customarily divided into four major economic zones including eastern, central, western and northeastern regions. There are not only geographical differences between them but also differences in resource endowments, economic and social development levels, which also lead to obvious differences in employment conditions, employment rates and employment policies. Affected by many factors such as labor supply and demand, regional natural resources and production efficiency in reality, the degree of labor transfer according to Petty-Clark's law is not balanced. The reform and opening up of the eastern region is early, the process of urbanization has accelerated, the demand for labor has exceeded supply, and the employment structure is more advanced. ${ }^{33}$ However, in the central, western and northeast region, the above conditions are far inferior to the eastern region. Therefore, the industrial structure upgrading in the eastern region had a significant impact on the income of the UEBMI.

The results of this paper showed that with the upgrading of the industrial structure, the per capita medical insurance expenditure had increased, which means that the average medical expenditure of the insured population has increased. There is no literature to study the impact of industrial structure on medical expenses or medical insurance expenditures. But the research of Blackwell et al and Ellis show that education level and income level have an important influence on the choice of medical treatment. $^{21,23}$ Cai and Wang a bibliometric analysis of all the literature on patients' medical choice in China from 2000 to 2017 finds that the top five factors affecting patients' medical choice preferences are economic income, education level, medical insurance payment method, age, and work status. ${ }^{51}$ Huang conducts a survey of 260 residents in Shanghai of China and finds that the groups with household incomes above 10,000 yuan are more inclined to choose tertiary medical institutions. ${ }^{25}$ Wang et al conducted a survey on medical choice behavior among residents in Beijing, Shanghai, Hangzhou, Shenyang, and Shenzhen. The results show that education, income, and insurance status are important factors influencing medical choice behavior, and each increase in income $1 \%$, compared with primary medical institutions, the probability of choosing a municipal medical institution increases by $64 \%$, and the probability of choosing a provincial medical institution increases by $53 \% .{ }^{52}$ Sun finds that the occupation type has an impact on the choice of patients. ${ }^{27}$ As mentioned above, when the industrial structure upgrades in a certain area, the education, income and work stability of the employed population will be greatly improved. This leads to changes in the choice of medical treatment for employees, which in turn increases the expenditure by the UEBMI. Therefore, the upgrading of industrial structure will lead to the increase of UEBMI's expenditure.

This paper found that ISUC2 had a positive impact on the expenditure of the UEBMI in mid-western and northeastern China. As mentioned above, the eastern region has better resource conditions than other regions, has absorbed a lot of people with high education level and income level, and the demand for medical treatment does not change much. While mid-western and north-eastern regions are in the development stage. With the improvement of their education level and income level, the release degree of medical demand will increases. Therefore, the industrial structure upgrading in mid-western and north-eastern China had a more significant impact on the expenditure of the UEBMI. In the context of industrial structure upgrading, both the income and the expenditure of UEBMI will rise, so it is not possible to relieve the payment pressure of UEBMI only through industrial structure upgrading. In addition, the research showed that the impact of industrial structure upgrading on the income 
and expenditure of UEBMI had regional differences. Therefore, this each region should formulate appropriate systems for the financing and reimbursement of the UEBMI, based on the development of that region.

In addition to the impact of industrial structure upgrading on the income and expenditure of UEBMI, the study also found that the proportion of retirees in the insured population had a significant positive impact on the income and expenditure of UEBMI. According to the relevant regulations of UEBMI, the employees must pay the medical insurance premium of enough fixed number of year, so they can get medical insurance reimbursement. ${ }^{47-50}$ China's UEBMI was established in 1998, with a relatively short history. Therefore, in recent years, the medical insurance premium that retires fill pay is more, resulting in the short-term increase of the per capita income of the UEBMI. However, with the increase of the establishment time of UEBMI and the retirees with insufficient fixed number of years finishing the medical insurance payment, the income of UEBMI will inevitably have an opposite relationship with the increase of the proportion of retirees. But the proportion of retirees was positively correlated with the expenditure of UEBMI, aging was still an important risk factor for employee medical insurance. Although China has established UEBMI system including SPA and MSAs. Due to management and other reasons, the medical insurance personal account did not realize the original intention of controlling medical expenses and accumulating medical funds. Therefore, the UEBMI in China is still pay-as-you-go in the actual operation process. With the emergence of declining birthrate in China and the deepening of the aging population, this risk will become greater and greater. In response to aging, China has fully implemented the two-child policy since 2016, and will completely liberalize childbirth in Northeast China on a trial basis. The literature has put forward policy recommendations for delaying retirement policies and for retirees to continue to pay appropriate insurance premiums. $^{36,37}$ The government should strengthen the scientific management of personal accounts to ensure their sound operation.

As for other factors affecting the expenditure of UEBMI, the research also showed that the dependency ratio of elderly population and the per capita GDP were positively correlated with the expenditure of UEBMI. This result was consistent with the previous literature of Ellis and Francia L. ${ }^{39,46}$ The research showed that the average salary of employed persons in urban units and the expenditure of the UEBMI were also important influencing factors in the per capita income of UEBMI. This was consistent with the research of Zhao; ${ }^{34} \mathrm{Cai}^{32} \mathrm{Gu}^{35}$, which show that average salsay level is postively correlated with medical insurance fund income.

The upgrading of the industrial structure promotes economic development and also changes all fields of society. This paper enriched our understanding of the impact of industrial structure upgrading on social security, and combined industrial structure upgrading with social medical insurance. The upgrading of industrial structure is a long process and an inevitable trend. This result reminds us, although the upgrading of the industrial structure will help increase medical insurance revenue and reduce the risk of medical insurance fund deficits, it will also promote the growth of medical insurance expenditure. Moreover, as a kind of consumption, medical treatment, like other consumption, is affected by the ratchet effect and is irreversible. When formulating social medical insurance plans, the government must not ignore the impact of industrial upgrading.

This paper has some important limitations. Firstly, China only began to disclose the income and expenditure data of the UEBMI at the provincial level in 2007. Therefore, because of the limited information available, this paper used the data from 2007 to 2018. Compared with the time course of industrial structure upgrading, the period of the data is relatively short. Secondly, As mentioned above, the impact of industrial structure upgrading on expenditure mainly comes from the changes in medical treatment behavior brought about by changes in the insured population structure. Due to the limited data available, it is impossible to incorporate the insured population characteristic variables into the model. The intermediate links of the impact mechanism had not been empirically tested. Last but not least, this article also did not include all influencing factors into the model, which may obscure some information.

\section{Conclusions}

This paper used China's provincial panel data from 2007 to 2018 to explore the impact of industrial structure upgrading on the income and expenditure of the UEBMI. Based on the analysis, we drew the following conclusions. Firstly, simple upgrading among the three major industries had no impact on the income and expenditure of the UEBMI. The upgrading of industrial structure when added to the internal upgrading of the tertiary sector had 
a positive impact on the income and expenditure of the UEBMI. Besides, there were regional differences in the impact on the income and expenditure of the UEBMI of the upgrading of the industrial structure when added to the internal upgrading of the tertiary industry. We should therefore consider the location of the regional industrial structure. Furthermore, the proportion of retirees in the insured population had a significant positive impact on the income and expenditure of UEBMI. Moreover, population aging and socio-economic development were still the main reasons for the increase of UEBMI expenditure. The average salary and the expenditure of the UEBMI were also important influencing factors in the per capita income of UEBMI. Measures such as strengthening employment and income security to guarantee the income of UEBMI, delaying retirement, adjusting birth policy and strengthening the scientific management of personal accounts should be taken in order to relieve the payment pressure of UEBMI.

\section{Data Sharing Statement}

This work contains statistical data from the National Bureau of Statistics of China. The data is available at https://data.stats.gov.cn/. The data accessed from National Bureau of Statistics of China is freely available.

\section{Ethical Approval}

There are no ethical concerns involved in this paper.

\section{Acknowledgments}

We are grateful to the following organizations who were involved in this study: National Natural Science Foundation of China (NSFC) for funding this project (71573182, 71974133); Beijing Municipal Natural Science Foundation also fund this project (9192004); the National Bureau of Statistics of China for providing access to data.

\section{Author Contributions}

All authors made a significant contribution to the work reported, whether that is in the conception, study design, execution, acquisition of data, analysis and interpretation, or in all these areas; took part in drafting, revising or critically reviewing the article; gave final approval of the version to be published; have agreed on the journal to which the article has been submitted; and agree to be accountable for all aspects of the work.

\section{Funding}

This research was supported by the National Natural Science Foundation of China (Grant No. 71974133 and 71573182) and Beijing Municipal Natural Science Foundation (Grant No. 9192004). No other relationships or activities that could appear to have influenced the submitted work.

\section{Disclosure}

The authors report no conflicts of interest in this work.

\section{References}

1. Cristina E. Changes in sectoral composition associated with economic growth. Int Econ Rev (Philadelphia). 1997. doi:10.2307/ 2527382

2. Simon K. Economic growth and income inequality. Am Econ Rev. 1955.

3. Zhang Y, He Y. Industrial structure change, factor reallocation and China's economic growth. Econ Survey. 2010;03:27-31. Chinese.

4. Shi D, Li P, Xu M. Industrial structural transformation and high-quality economic development. Fujian Tribune. 2020;09:108-118. Chinese.

5. Bech M, Christiansen T, Khoman E, Lauridsen J, Weale M. Ageing and health care expenditure in EU-15. Eur J Health Econ. 2011;12 (5):469-478. doi:10.1007/s10198-010-0260-4

6. Gerdtham UG, Søgaard J, Andersson F, Jönsson B. An econometric analysis of health care expenditure: a cross-section study of the OECD countries. J Health Econ. 1992;11(1):63-84. doi:10.1016/ 0167-6296(92)90025-v

7. Huang A, Fang P, Shen M, et al. Analysis on the impacts of demographic factors on medical insurance fund expenditure. Chin Health Econ. 2018;37(6):33-36. Chinese.

8. Li J, Fang P, Chen W, et al. Analysis on the effects of economic development level, aging population degree and rising medical costs on medical insurance fund expenditure in China. Chin Health Econ. 2017;36(1):27-29. Chinese.

9. Newhouse JP. Medical care costs: how much welfare loss? J Econ Perspect. 1992;6(3):3-21. doi:10.1257/jep.6.3.3

10. Tao Y, Wang Q. The empirical analysis of china's social medical insurance costs. Chin Health Econ. 2010;29(06):18-21. Chinese.

11. Wallner PE, Konski A. The impact of technology on health care cost and policy development. Semin Radiat Oncol. 2008;18(3):194-200. doi:10.1016/j.semradonc.2008.01.007

12. $\mathrm{Xu}$ Y. Study on the urban employee's basic medical insurance fund balance and its influencing factors-an empirial analysis based on $\mathrm{T}$ city. Southwest Univ Finance Econ. 2014. Chinese.

13. Mi H, Zhu X, Fang R. Analysis of the adaptability of the level of social security and industrial restructuring. J Northwest A\&F Univ. 2008;02:92-97. Chinese.

14. Mu H, Fan L. Research on effects of industrial structure's upgrading on reducing pension contribution's space. J Hebei Univ. 2017;42 (06):93-101. Chinese

15. Fu Z, Liao S, Li Y. Analysis on the influence of industrial structure adjustment and the basic endowment insurence development in Shandong. J Shandong Technol and Business Univ. 2018;32 (01):89-103. Chinese.

16. Dong C, Wang B. A study on the correlation between industry structure and employment structure in Shaanxi Province. J Xi'an Pet Inst. 2002; 2. Chinese.

17. Yuan W, Wang H, Liu P. The study on the related problems of industrial structure and employment structure in Hebei Province. J Hebei Univ. 2012;37(05):65-69. Chinese. 
18. Han F, Deng G. Restructuring and employment expansion-A strategic study of industrial structure and employment structure in Hebei Province. J Hebei Normal Univ. 2005;01:41-47. Chinese.

19. Drucker J. An evaluation of competitive industrial structure and regional manufacturing employment change. Reg Stud. 2015;49 (9):1481-1496. doi:10.1080/00343404.2013.837874

20. Hannon E, Monks K, Conway E, et al. The state and industrial policy in Ireland: a case study of the Irish pharmaceutical sector. Int J Human Resour Manage. 2011;22(18):3692-3710. doi:10.1080/ 09585192.2011.622918

21. Blackwell DL, Martinez ME, Gentleman JF, et al. Socioeconomic status and utilization of health care services in canada and the United States: findings from a binational health survey. Med Care. 2009;47 (11):1136-1146. doi:10.1097/MLR.0b013e3181adcbe9

22. Borah BJ. A mixed logit model of health care provider choice: analysis of NSS data for rural India. Health Econ. 2006;15 (9):915-932. doi:10.1002/hec.1166

23. Ellis RP, Mcinnes DK, Stephenson EH. Inpatient and outpatient health care demand in Cairo, Egypt. Health Econ. 1994;3 (3):183-200. doi:10.1002/hec.4730030307

24. Gao Y. A study on the influencing factors of resident's choice of medical institutions and the gap between willingness and behavior in hierarchic care. East China Normal Univ. 2020. Chinese.

25. Huang J. Analysis on the influencing factors of Shanghai residents' hospital selection behavior. Shanghai Jiaotong Univ. 2017. Chinese.

26. Majaj L, Nassar M, Allegri MD. It's not easy to acknowledge that I'm ill': a qualitative investigation into the health seeking behavior of rural Palestinian women. Bmc Womens Health. 2013;13. doi:10.1186/ 1472-6874-13-26

27. Sun C. The Analysis of patient choice behavior based on discrete choice experiment. Beijing Inst Technol. 2016. Chinese.

28. Xu M, Jiang Y. Can the China's industrial structure upgrading narrow the gap between urban and rural consumption? J Quant \& Tech Econ. 2015;32(03):3-21. Chinese.

29. Wang W, Liu Y, Peng D. Research on effects of population aging on industrial upgrading. China Ind Econ. 2015;11:47-61. Chinese.

30. Suen RMH. Technological advance and the growth in health care spending. Economied'Avant Garde Res. 2005.

31. Huang A. Study on influencing factors and evaluation of sustainable development ability of urban employees' basic medical insurance fund based on PSR model. Huazhong Univ Sci Technol. 2019. Chinese.

32. Cai Q. The study on influencing factors of basic medical insurance fund balance for urban workers in Shaanxi Province. Northwest Univ. 2019. Chinese.

33. Gao Y, Lin D, Lin Y. An empirical analysis on the influencing factors of reemployment and regional differences of employment structure in China. Productivity Res. 2012;(03):120-122. Chinese.

34. Zhao H. Study on the influencing factors of the income and expenditure of the basic medical insurance fund for urban workers. Sci Wealth. 2015;7(29):104. Chinese.

35. Gu Y. Forecast and influencing factors research of basic medical insurance fund for urban workers on income and expenditure. Guangdong Pharm Univ. 2019. Chinese.
36. Cao C. Rationality of retired worker's payment of medical insurance expense. Modern Business Trade Industry. 2016;37(28):77-80. Chinese.

37. Huang Z. Research on policy of delayed retirement, old-age labor supply and urban-rural income gap-an empirical analysis based on inter-provincial data of China. 2018 2nd International Conference on Education Science and Economic Management (ICESEM 2018).2018.

38. Huang F, Gan L. Impact of China's urban employee basic medical insurance on health care expenditure and health outcomes. NBER Working Papers. 2015.

39. Ellis RP, Fiebig DG, Johar M, et al. Explaining health care expenditure variation: large-sample evidence using linked survey and health administrative data. Health Econ. 2013;22(9):1093-1110. doi:10.10 02/hec. 2916

40. Jia H, Zhao D. Study on the influence of population aging on the balance of basic medical insurance funds of urban employees based on the evdience of provincial panel data from 2004 to 2015. Shanghai J Econ. 2017;10:38-46. Chinese.

41. Barber SL, Yao L. Health insurance systems in China: a briefing note. World Health Rep. 2010.

42. Yang $\mathrm{C}, \mathrm{He} \mathrm{W}$. Study on the adaptability relation between social security level and economy development. J Public Management. 2004;01:79-85+96. Chinese.

43. Xu T. Research on coordinated development of industrial structure and employment structure in inner Mongolia. Northwest Minzu Univ. 2020. Chinese.

44. Behera DK, Dash U. Impact of GDP and tax revenue on health care financing: an empirical investigation from Indian states. Theor Appl Econ. 2017;XXIV(2):249-262.

45. Rahman, Tauhidur. Determinants of public health expenditure: some evidence from Indian states. Appl Econ Lett. 2008;15(11):853-857. doi:10.1080/13504850600770970

46. Francia L, Gitto L, Mennini FS, et al. An econometric analysis of OECD countries health expenditure. Soc Sci Electron Publ. 2007.

47. Zhai F. Reconsideration on the premium policy of medical insurance for retired workers and its theoretical disputes in China. China $J$ Health Policy. 2018;11(01):6-12. Chinese.

48. Xiang C. Duration of payment and medical security for retirees. China Soc Secur. 2017;03:70-71. Chinese.

49. Zhai S, Yan J. The policy of payment duration should be designed reasonably. China Soc Secur. 2017;03:72-73. Chinese.

50. Tan Z. Thinking on improving the mechanism for employee basic medical insurance fundraising. China Health Insur. 2016;05:13-17. Chinese.

51. Cai J, Wang J. Features and influencing factors of patient values and preferences for medical choice in China: a bibliometric analysis. Guangxi Med J. 2019;41(17):2206-2210. Chinese.

52. Wang M, Zhang Y, Wang J. Analysis of the factors affecting individuals' hospital choice for medical consultation in urban China-a case study of five cities. J Taishan Med college. 2012;33(06):447-450. Chinese.

\section{Publish your work in this journal}

Risk Management and Healthcare Policy is an international, peerreviewed, open access journal focusing on all aspects of public health, policy, and preventative measures to promote good health and improve morbidity and mortality in the population. The journal welcomes submitted papers covering original research, basic science, clinical \& epidemiological studies, reviews and evaluations,

guidelines, expert opinion and commentary, case reports and extended reports. The manuscript management system is completely online and includes a very quick and fair peer-review system, which is all easy to use. Visit http://www.dovepress.com/testimonials.php to read real quotes from published authors. 